\title{
Differential Proteome Expression of In vitro Proliferating Bovine Satellite Cells from Longissimus Dorsi, Deep Pectoral and Semitendinosus Muscle Depots in Response to Hormone Deprivation and Addition
}

\author{
Ramanna Valmiki Rajesh*, Seong Kon Kim*, Mi Rim Park*, Min Ah Park***, Eun Joung Jang*, Seung Gu Hong**,
} Jong Soo Chang***, Duhak Yoon*, Tae Hun Kim* and Hyun Jeong Lee*

Division of Animal Genomics and Bioinformatics, National Institute of Animal Science, R.D.A.*, Nutrition and Physiology Team, National Institute of Animal Science, R.D.A.**, Dept. of Agricultural Science, Korea National Open University***

\begin{abstract}
The aim of this study was to analyze the proteome of proliferating bovine satellite cells from longissimus dorsi, deep pectoral and semitendinosus muscle depots which had been subjected to hormonal deprivation or addition in culture. For hormone deprivation or addition studies, the cells were either grown in $10 \%$ charcoal-dextran stripped fetal bovine serum (CD-FBS) or in $10 \%$ FBS supplemented medium. Further to analyze the effect of insulin like growth factor (IGF-1) and testosterone (TS), the cells were grown in $10 \%$ CD-FBS containing IGF-1 $(10 \mathrm{ng} / \mathrm{ml})$ or TS $(10 \mathrm{nM})$. Results have shown that hormone deprivation had a negative impact on proliferation of the cells from each of the muscle depots. In case of IGF-1 and TS addition, the proliferation levels were low compared with that of the cells grown in $10 \%$ FBS. Hence, to gain the insights of the proteins that are involved in such divergent levels of proliferation, the proteome of such satellite cells proliferating under the above mentioned conditions were analyzed using 2D-DIGE and MALDI-ToF/ToF. Thirteen proteins during hormone deprivation and nine proteins from hormone addition were found to be differentially expressed in all the cultures of the cells from the three depots. Moreover, the results highlighted in this study offer a role for each differentially expressed protein with respect to its effect on positive or negative regulation of cell proliferation.
\end{abstract}

(Key words : Satellite cells, Depot, Proliferation, Hormone)

\section{INTRODUCTION}

Skeletal muscle is a tissue of major economic importance for meat production. Muscle fiber growth, along with the hormones which affect the growth of muscle tissue are important for meat industry (Campion, 1984). The number of muscle fibers in meat-producing animals is essentially fixed at birth, thus postnatal muscle growth results from hypertrophy of existing muscle fibers (Kamanga-Sollo et al, 2008). This fiber hypertrophy requires an increase in the number of myonuclei present in the fibers. However, the nuclei present in muscle fibers are unable to divide, so the nuclei must come from outside the fiber (Campion, 1984). The source of the nuclei needed to support fiber hyperplasia (cell proliferation) is mononucleated myogenic cells, satellite cells, located on the periphery of the fiber (Moss and Leblond, 1971). Muscle satellite cells play a crucial role in the postnatal muscle growth by fusing with existing muscle fibers and providing the nuclei required for postnatal fiber growth (Campion, 1984 Moss and Leblond, 1971).

A better understanding of the involvement of satellite cells in postnatal muscle hyperplasia represents a powerful key to improve the efficiency of muscle growth in meat-producing animals. Nevertheless, regulation of satellite cell activity in vivo is complex. Satellite cells may be regulated through extrinsic factors such as the innervation, hormonal signal, or locally produced growth factors (Allen and Rankin, 1990 Dodson et al, 1996). Among growth factors are the fibroblast growth factors (FGFs), insulin-like growth factors (IGFs), transforming growth factor $b$ (TGFb), epidermal growth factor (EGF), platelet-derived growth factor (PDGF), or hepatocyte growth factor (HGF) (Allen et al, 1995). Even though satellite cells are regulated through diffusible factors arising from the fibers rather than through circulating factors, satellite cells may also be activated under nutritional (Hansen-Smith et al, 1979) or hormonal manipulation (McCuscker and Campion, 1986; Thompson et al, 1989). There are few reports about hormonal regulation of meat-animal satellite cells. Several

Corresponding author:Hyun Jeong Lee, Animal Genomics and Bioinformatics Division, National Institute of Animal Science, Rural Development Administration, \#564 Omockchun-dong, Suwon, 441-706, Korea. Tel: +82-31-290-1594, Fax: + 82-31-290-1594, E-mail: hyunj68@korea.kr 
hormones have been shown to affect the proliferation and differentiation of both primary satellite cells from bovine (Kamanga-Sollo et al, 2008) and rat (Allen and Boxhorn, 1987), along with myogenic cell lines (Florini and Magri, 1989). Androgenic and estrogenic implants are widely used, both individually and in combination, as growth promoters for cattle (Hayden et al, 1993; Johnson et al, 1996). Also, it was shown that artificial implantation of growth hormones increased the number of satellite cells (Johnson et al, 1998). Additionally, a number of studies in humans and animals have shown that hormone treatment increases the muscle fiber diameter. The number of myonuclei present in the muscle fibers was also shown to be increased (Bhasin et al, 2001; Sinha-Hikim et al, 2002, 2003). Also, it was shown that muscle satellite cells were subjected to apoptosis during serum deprivation (Mampuru et al, 1996), but all of these studies lack proteomic approach to elucidate the proteins that are involved in such a cell death process. Hence, the aim of this work was to look for muscle depot related differences for differentially expressed proteins in relation to proliferation under hormone deprivation and addition conditions. So, this study detail the comparison of growth rate and DIGE (Fluorescence Difference Gel Electrophoresis) dependent proteomic characterization during hormone deprivation and addition on proliferating satellite cells from bovine longissimus dorsi(LD), deep pectoral (DP) and semitendinosus (ST) muscle depots.

\section{MATERIALS AND METHODS}

\section{Animals}

Five heads of Hanwoo (Korean cattle) steers were fed and managed at feeding barn in the National Institute of Animal Science under the high quality beef production program (1997) and slaughtered at 24 months of age. All experimental procedures and the care of animals were conducted in accordance with the guidelines of the Animal Care and Use Committee (IACUC) of the National Institute of Animal Science in Korea.

\section{Cell preparation}

Animal experimentation was approved by the Animal Care and Concern committee of the National Institute of Animal Science, in Suwon.

Satellite cells were isolated from the three bovine muscle depots (longissimus dorsi, deep pectoral and semitendinosus) as described by Doumit and Merkel (1992). Briefly, the muscles were excised, trimmed of visible connective tissue, and minced with fine sharp scissors. One gram of minced muscle was incubated for $50 \mathrm{~min}$ at $37^{\circ} \mathrm{C}$ in a solution of protease $(4 \mathrm{mg} / \mathrm{ml})$ in PBS. After enzymatic digestion, the cells were separated from the tissue fragments by reapted centrifugation at 1200 and $300 \times \mathrm{g}$ for 15 and $5 \mathrm{~min}$ respectively, followed by filtration using mash nylon cloth. Thereafter, the filtrate was further centrifuged at 1200 $\times \mathrm{g}$ for $15 \mathrm{~min}$ and the pellet was collected and reconstituted with DMEM medium supplemented with 10\% Fetal Bovine Serum, penicillin $(100 \mathrm{U} / \mathrm{ml})$ and streptomycin $(100 \mu \mathrm{g} / \mathrm{ml})$ and seeded in $10 \mathrm{~cm}$ petri-dish at a density of approximately $1 \times 10^{4}$ cells $/ \mathrm{cm}^{2}$. The cells were incubated at $37^{\circ} \mathrm{C}$ in $5 \% \mathrm{CO}_{2}$ in air. Subsequently, the cells were cultured in a medium containing $10 \%$ charcoal dextran stripped fetal bovine serum(CD-FBS; Gibco-BRL) supplemented medium, together with IGF-1 (10 ng/ml), TS (10 $\mathrm{nM})$. The medium was changed every second day allowing the cells to proliferate until confluence (about 9 days).

\section{Cell Counting}

Cell number was determined at day 3, 6, and 9 post plating. Cell cultures were washed three times with saline, then trypsinized with calcium and magnesium free Hank's solution containing $0.2 \%$ trypsin and finally counted in a "Countess Automated Cell Counter" from Invitrogen Ltd, USA. Cell viability was assessed by trypan blue exclusion. Whatever their anatomical origin, $95 \%$ of cells excluded trypan blue.

\section{2D-DIGE (2-dimensional gel electrophoresis / Fluore- scence Difference Gel Electrophoresis)}

\section{(1) Protein preparation and 2D-DIGE}

Proteins from proliferating satellite cells $\left(9^{\text {th }}\right.$ day) were extracted on ice for at least $30 \mathrm{~min}$ with $30 \mu \mathrm{l}$ lysis buffer ( $\mathrm{pH} 8.5$ ) containing $7 \mathrm{M}$ urea, $2 \mathrm{M}$ thiourea, $30 \mathrm{mM}$ Tris and $4 \%$ CHAPS (Rabilloud, 1998). Following the centrifugation at $20000 \times \mathrm{g}$ for $20 \mathrm{~min}$ at $4^{\circ} \mathrm{C}$, the supernatant was removed and the pellets were collected and then completely dried using speed-vac. Dried samples were redissolved in the 2-DE sample buffer (7M Urea, 2M Thiourea, 2\% CHAPS, $100 \mathrm{mM}$ DTT, 0.5\% pH 3-10NL IPG buffer). Then the concentration of total protein in the sample was determined by 2D-Quant Kit (GE healthcare), using BSA as a standard. $50 \mu \mathrm{g}$ of protein per sample were labeled with $400 \mathrm{pmol}$ of $\mathrm{Cy} 3$ or $\mathrm{Cy} 5$ or $\mathrm{Cy} 2$ (internal standard) (CyDyes, GE Healthcare) for $30 \mathrm{~min}$ on ice in the dark. After the labeling reaction with $1 \mu \mathrm{l}$ lysine $(10 \mathrm{mM})$ for $10 \mathrm{~min}$, the differently 
labeled samples were pooled with $50 \mu \mathrm{g}$ of unlabeled, equal amount of each sample mixture and then mixed with a double volume of rehydration buffer (7 M urea, $2 \mathrm{M}$ thiourea, $4 \%$ CHAPS, $2 \%$ (v/v) IPG buffer pH 3-10 and $2 \%$ (w/v) DTT). The mixed samples were applied onto $24 \mathrm{~cm}$ IPG non-linear $\mathrm{pH}$ 3-10 gel strips, which had been rehydrated at $20^{\circ} \mathrm{C}$ for at least $10 \mathrm{~h}$ in $450 \mu \mathrm{l}$ DeStreak solution (GE Healthcare) with $0.5 \%$ (v/v) IPG buffer $\mathrm{pH}$ 3-10 NL. Isoelectric focusing (IEF) was carried out for a total of $88 \mathrm{kVh}$ at $20^{\circ} \mathrm{C}$ in five steps with a gradual increase of voltage $(300 \mathrm{~V}$ for $4 \mathrm{~h}, 600 \mathrm{~V}$ for $4 \mathrm{~h}$, gradient from $600 \mathrm{~V}$ to $1000 \mathrm{~V}$ for $4 \mathrm{~h}$, gradient from $1000 \mathrm{~V}$ to $5000 \mathrm{~V}$ for $4 \mathrm{~h}$ and to total $8000 \mathrm{Vhr}$ ) using the IPG phor 3 system (GE Healthcare). For the second dimension, the IPG strips were first reduced for $15 \mathrm{~min}$ in SDS-equilibrium buffer (6 M urea, $50 \mathrm{mM}$ Tris- $\mathrm{HCl}$, $\mathrm{pH} 8.8$, $30 \%$ glycerol, $2 \%$ SDS, trace of bromophenol blue and $0.5 \%$ $(\mathrm{w} / \mathrm{v}) \mathrm{DTT}$ ) and then carbamidomethylated for $15 \mathrm{~min}$ in the same buffer containing $4.5 \%(\mathrm{w} / \mathrm{v})$ iodoacetamide instead of DTT. The second dimension was performed on $12 \%$ polyacrylamide gels $(20 \times 24 \mathrm{~cm})$ using the Ettan Dalt six system (GE Healthcare) at $10 \mathrm{~mA}$ per gel for $1 \mathrm{~h}$, and then with an increased current of 15 $\mathrm{mA}$ per gel until the bromophenol blue band reached the end of the gel cassette. Electrophoresis was carried out under continuous cooling at $15^{\circ} \mathrm{C}$.

\section{(2) Gel image analysis and spotting}

The in-gel fluorescence was scanned on a Typhoon 9400 (GE Healthcare) at appropriate wavelengths to detect $\mathrm{Cy} 3$ and $\mathrm{Cy} 5$ specific emission corresponding to the protein concentration in every single spot (Tongeet al, 2001). The intragel spot detection of the multiplexed gel images was performed using differential in-gel analysis (DIA) included in the DeCyder 6.5 software (GE Healthcare). The images for each gel were merged; spot boundaries were detected followed by a normalization of the spot volumes revealing differential spots. One-way analysis of variance, ANOVA, was adopted to determine significant protein expression differences among proliferating BSC from three depots. Subsequently, significantly under or over-expressed proteins were identified by multiple comparisons using the Student's t-test. For protein identification the gels were stained with Flamingo Pink (Bio Rad) according to the manufactures instructions. Spots of interest were selected on the gel by comparing with the pattern of the 2D-DIGE protein pattern. The selected spots were excised from gels using a punch and placed in $500 \mu l$ eppendorff tubes. In-gel tryptic digestion and mass spectrometry were followed.

\section{Protein identification}

The spots were excised from gels using a punch and placed in $500 \mu \mathrm{l}$ Eppendorf tubes. The proteins were digested in-gel with trypsin as described by Hellmann et al. (1995). Briefly, each spot was destained with $50 \mu \mathrm{l} 50 \%$ acetonitrile (ACN) in $50 \mathrm{mM}$ $\mathrm{NH}_{4} \mathrm{HCO}_{3}$, incubated at $37^{\circ} \mathrm{C}$ for $30 \mathrm{~min}$ and repeated once. Then the gels were reduced and alkylated. The gel pieces were digested overnight with trypsin $(20 \mu \mathrm{g} / \mu \mathrm{l})$ in $50 \mathrm{mM} \mathrm{NH}_{4} \mathrm{HCO}_{3}$ containing $10 \%$ ACN. The digest was then vortexed for $30 \mathrm{~min}$ and dried using speed vac. The dried extracted peptides were resuspended in a $1 \mu 1$ solution containing pure water:ACN:trifluoracetic acid (TFA) (93:5:2).

Solution-phase nitrocellulose target preparation was used according to the method reported by Landry et al . (2000). acyano-4-hydroxycinnanic acid (CHCA) $(40 \mathrm{mg} / \mathrm{ml})$ and nitrocellulose $(20 \mathrm{mg} / \mathrm{ml})$ were prepared separately in acetone and mixed with 2-propanol at a ratio of 2:1:1. The matrix solution was mixed with the sample at a ratio of $1: 1$, then $0.5-0.3 \mu \mathrm{l}$ was spotted onto the target and dried. The immobilized samples were washed with $1 \%$ formic acid twice and samples were then dried for the second time prior to the MALDI-TOF-MS/MS analysis.

Sample peptide masses were obtained using the Applied Biosystems 4700 Proteomics analyzer MALDI-TOF/TOF mass spectrometer (Applied Biosystems) in the positive ion reflector mode. MS/MS analysis was performed on the 5 most abundant ions and the proteins were identified by searching the SWISSPROT and National Center for Biotechnology Information databases using the Mascot programs (Matrix Science, London, UK). Mass accuracy was considered to be within $50 \mathrm{ppm}$ for peptide mass analysis and within $100 \mathrm{ppm}$ for MS/MS analysis. For protein identification, known contamination peaks such as those of keratin and auto proteolytic were removed, and molecular weight, pI and protein scores were considered.

\section{RNA isolation and real-time RT-PCR analysis}

Total RNA was isolated from the cells using TRIzol reagent (Invitrogen Co., Carlsbad) based on the manufacturer's description. The first strand of cDNA was synthesized using $2 \mu \mathrm{g}$ of total RNA as a template, oligo-dT primer and Reverse Transcriptase (Invitrogen Co.) according to the manufacturer's instructions. Measurement of the relative quantity of the cDNA of interest was carried out using SYBR Green PCR Master Mix (Applied Biosystems), $300 \mathrm{nM}$ of the appropriate forward and reverse primers, and $1 \mathrm{ml}$ of the cDNA mixture. The sequence of 
forward and reverse primers used for detection of MyoD, Myogenin and My5 are given in table 1.

\section{RESULTS}

1. Effect of hormone deprivation and addition on proliferation of satellite cells from bovine longissimus dorsi, deep pectoral and semitendinosus

Satellite cells were isolated from bovine longissimus dorsi, deep pectoral and semitendinosus muscle depots, further to check the isolated and proliferated cells are satellite cells, real time PCR analysis was performed for MyoD, Myogenin and My5 genes known as marker genes for muscle satellite cells (Cooper et al, 1999 Allen et al, 1990). Fig. 1 details the real-time PCR analysis, and from the figure it is clear that all the isolated cells from three depots were having considerable mRNA levels of above mentioned marker genes, further elucidating the evidence for the presence of satellite in our experiments. The growth rate of bovine satellite cells (BSC) from longissimus dorsi, deep pectoral and semitendinosus muscle depots grown in hormone deprived medium (10\% CD-FBS) and 10\% FBS was determined from day 1 to 9 after plating. Fig. 2 shows the growth rate of BSC from three depots on $9^{\text {th }}$ day. The purpose of showing the data of day 9 is that, we have taken the BSC at $9^{\text {th }}$ day for our proteomic analysis and to compare with our proteomic output with the growth rate of BSC, we choose to represent day 9 growth rate data in Fig. 2. The BSC from all the three depots showed higher growth rates in $10 \%$ FBS in comparison to $10 \%$ CD-FBS. In fact, the growth rate of BSC from all the depots was increased at least by a factor of two $(p<0.05)$ in FBS than in CD-FBS. Thus the presence or absence of hormones (CD-FBS were shown to have less concentrations of important hormones such as estrogen, cortisone and progesterone as per manufacturer's instructions) influence the growth of BSC. However, while comparing the growth of $\mathrm{BSC}$ in $10 \% \mathrm{FBS}$ among the depots, the growth rate was more in LD followed by PC and ST BSC, respectively.

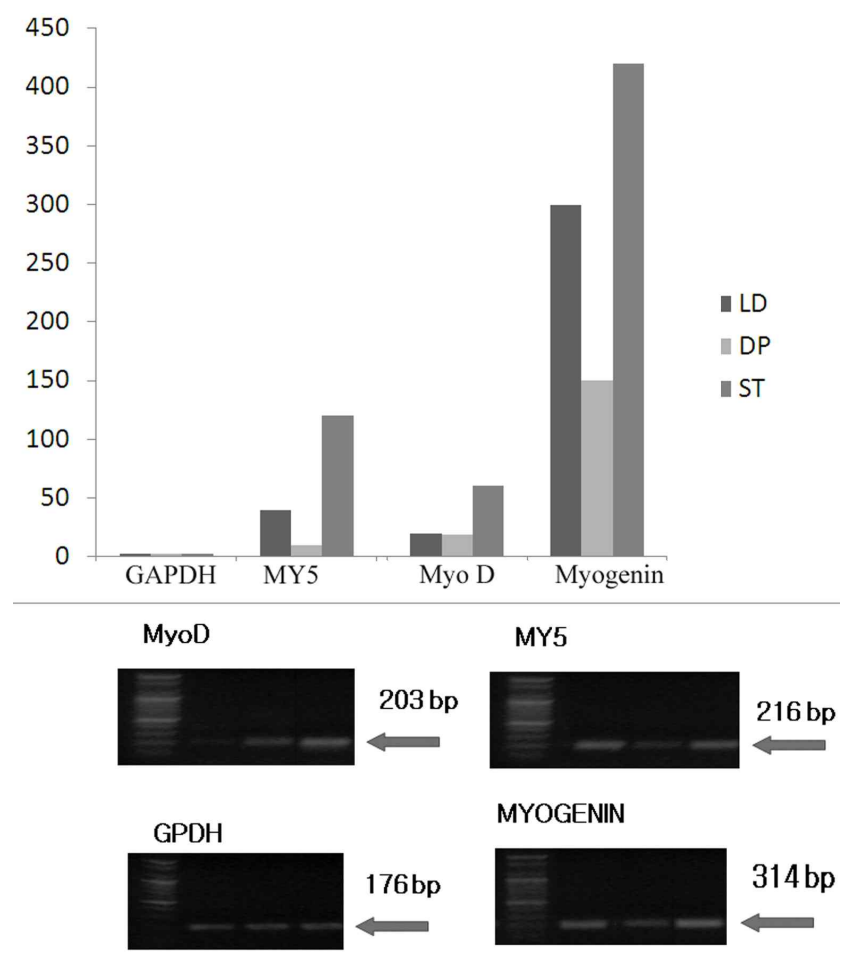

Fig. 1. RT-PCR and relative mRNA levels of MyoD, Myogenin and My5 genes in total RNA isolated from proliferating BSC cultures at day 9 from longissimusdorsi (LD), deep pectoral (DP) and semitendinosus (ST) muscle depots. The data points in the figure are from individual assays were the average of mRNA levels obtained from triplicate cultures.

However, the above experiment does not establish the effect of any particular hormone on the growth rate of BSC. This prompted us to compare the BSC proliferation rates with effect to the addition of well known cell proliferators IGF-1 or TS to the medium containing 10\% CD-FBS. Fig. 2 displays the growth rate, and addition of either one of the hormones were found to have lesser growth rates in comparison to the BSC grown in 10\% FBS. All the BSC from three depots, grown either in 10\% CD-FBS with IGF-1/TS were showing similar or less growth rates in

Table 1. Sequence of primers used in RT-PCR

\begin{tabular}{lllc}
\hline Gene Name & \multicolumn{1}{c}{ Forward primer } & Reverse primer & Product size (bp) \\
\hline \hline GAPDH & gggtcatcatctctgcacct & ggtcataagtccctccacga & 176 \\
MY5 & ctcaggaatgccatccgctacattgaga & atccaagctggataaggagcttttatccg & 216 \\
MyoD & atcctgcgcaacgccatccgctatatcga & ctcgcgctgtagtaagtgcggtcgtagcagt & 203 \\
Myogenin & gagaagcgcagactcaagaaggtgaatga & tctgtagggtccgctgggagcagatgatc & 314 \\
\hline
\end{tabular}




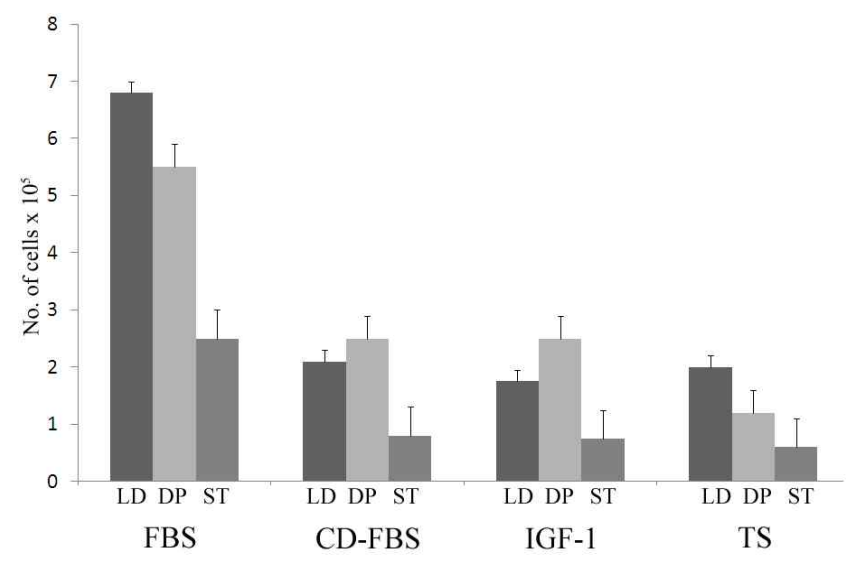

Fig. 2. Influence of hormone deprivation and addition on the growth rate of BSC from longissimus dorsi, deep pectoral and semitendinosus muscle depots. BSC from three depots were prepared and plated in medium containing $10 \%$ CD-FBS or $10 \%$ FBS and $10 \%$ CD-FBS containing IGF-1/TS. At day 9, cells were collected and counted as mentioned in methods. Comparison of the growth rate between BSC from longissimus dorsi, deep pectoral and semitendinosus muscle depots were expressed here are the mean \pm SEM of triplicate experiments represented in the error bars.

comparison to CD-FBS alone. Hence, we here consider that the proteins that are expressed under these conditions (CD-FBS alone or with IGF-1/TS addition) may be involved in inhibition of proliferation or in cell death. Hence, to understand this unusual behavior of BSC, we analyzed the proteome of the proliferating BSC from three depots at all treated conditions using 2D-DIGE coupled with MS for the identification of differentially expressed proteins, which may play a crucial role in determining the proliferation of BSC.

2. Differential protein expression of bovine satellite cells from longissimus dorsi, deep pectoral and semitendinosus muscle depots grown in hormone deprivation and addition conditions

To investigate the differences in protein expression of BSC grown in hormone deprivation and addition conditions, whole protein extracts of BSC from three depots grown in $10 \%$ FBS or $10 \%$ CD-FBS with IGF-1/TS were separated by 2D-DIGE. For our proteomic analysis, we choose the BSC from day 9, as the maximum difference in growth rate was observed. According to the DeCyder program used for analyzing the spots, differentially expressed proteins were identified. Spots which exhibited significant differential expression during proliferation at various conditions (t-test, $p<0.05$ ), were isolated for more detailed characterization from the gel stained with Flamingo pink. Comparison of protein samples from BSC grown in $10 \%$ FBS and CD-FBS, showed thirteen different proteins to have the differential expression. All the proteins across three depots were found to have lower expressions. Protein PRO0628, Transgelin, Vimentin, UPF0279 protein C14orf129 and actin in LD; DGCR8 protein, stress-70 protein, plasminogen, inward rectifier potassium

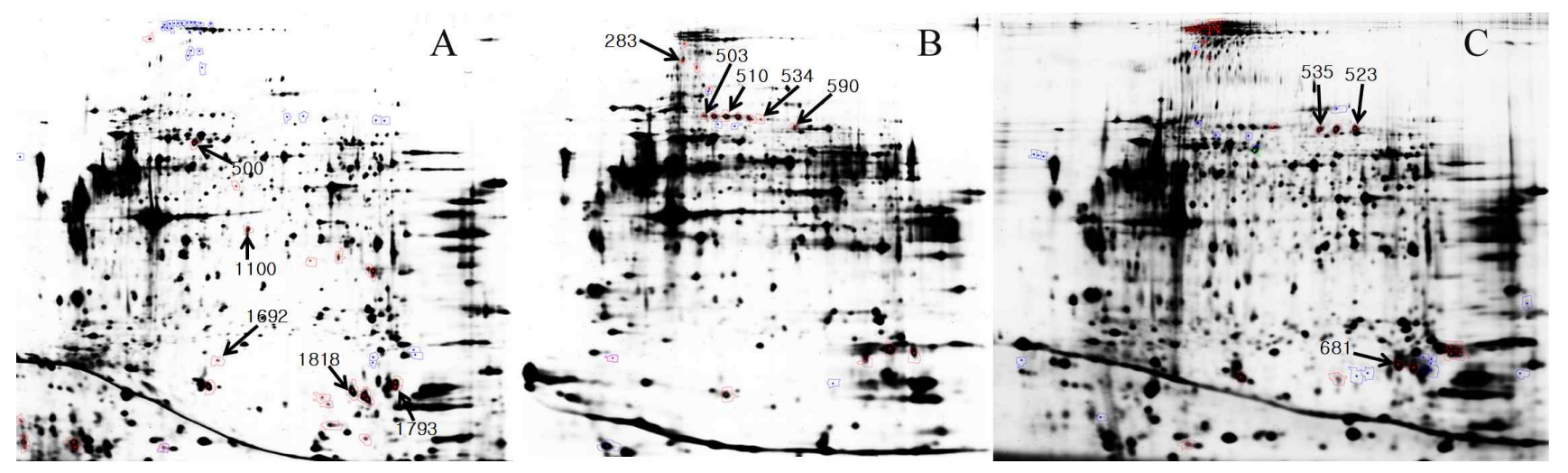

Fig. 3. 2D-DIGE of BSC proteins. Protein extracts of BSC from longissimus dorsi, deep pectoral and semitendinosus muscle depots grown in 10\% CD-FBS or 10\% FBS supplemented medium (day 9) were labeled with CyDyes Cy3, Cy5 and Cy2, respectively, and were mixed and separated on a 2-DE gel using $24 \mathrm{~cm} \mathrm{pH} \mathrm{3-10} \mathrm{NL} \mathrm{strips} \mathrm{in} \mathrm{the} \mathrm{first} \mathrm{dimension} \mathrm{and} \mathrm{12 \%} \mathrm{SDS-PAGE} \mathrm{gels} \mathrm{in} \mathrm{the} \mathrm{second} \mathrm{dimension.}$ Gels were scanned to obtain single images, and the figures represented here are the overlay of the two dyes (Cy3, Cy5) of longissimus dorsi (A), deep pectoral (B) and semitendinosus (C) BSC proteins. The same gel, after fluorescence imaging, was stained with Flamingo pink and scanned. Differentially expressed protein spots as indicated in Table 2 are represented in the corresponding gels with arrows. 
channel 16 and $116 \mathrm{kDa}$ U5 small nuclear ribonucleoprotein in DP; Run and FYVE domain-containing protein 1, lactotransferrin precursor and triose-phosphate isomerase in ST were found to be decreased during proliferation (Fig. 3, Table 2).

In case of IGF-1/TS addition, nine proteins were found to be differently expressed across three depots. Uncharacterized protein
C2orf10, C-jun-amino-terminal kinase-interacting protein 4, interleukin-8 receptor A, tryptophan 5-hydroxylase 1 and dihydropyrimidinase-realted protein 2 in LD was found be decreased. In DP, vimentin and tubulin are expressed low, while hemoglobin subunit epsilon was highly expressed. Only, the collagen alpha-5 chain precursor was highly expressed in ST (Fig. 4, Table 3).

Table 2. Differentially expressed proteins from FBS/CD-FBS treated bovine satellite cells from longissimus dorsi, deep pectoral and semitendinosus muscle depots

\begin{tabular}{rrrcccc}
\hline No. & Spot No. & Abundance & Protein Name & Protein Score & Protein score \% & Fold change \\
\hline \hline 1 & 1818 & Decreased & Protein PRO0628 & 47.1 & 12.5611 & 0.6 \\
2 & 1793 & Decreased & Transgelin & 76.2 & 99.892 & 1.2 \\
3 & 1692 & Decreased & Vimentin & 111 & 100 & 1.1 \\
4 & 500 & Decreased & UPF0279 protein C14orf129 & 49.8 & 53.042 & 0.5 \\
5 & 1100 & Decreased & Actin, cytoplasmic 1 & 70.7 & 99.61832 & 2.8 \\
6 & 283 & Decreased & DGCR8 protein & 48.1 & 30.544 & 1.3 \\
7 & 534 & Decreased & Stress-70 protein, mitochondrial precursor & 85.3 & 99.98 & 0.9 \\
8 & 503 & Decreased & Plasminogen & 49.8 & 53.04 & 1.2 \\
9 & 510 & Decreased & Inward rectifier potassium channel 16 & 47.6 & 22.07 & 3.1 \\
10 & 590 & Decreased & 116 kDa U5 small nuclear ribonucleoprotein & 57.6 & 22.222 & 0.8 \\
11 & 523 & Decreased & RUN and FYVE domain-containing protein 1 & 46.6 & 1.89 & 0.4 \\
12 & 535 & Decreased & Lactotransferrin precursor & 49.9 & 54.111 & 0.8 \\
13 & 681 & Decreased & Triosephosphate isomerase & 59 & 94.354 & 1.2 \\
\hline
\end{tabular}

Differential protein expression from bovine longissimus dorsi (S No. 1 to 5); deep pectoral (S No. 6 to 10); semitendinosus (S No. 11 to 13) muscle depots.
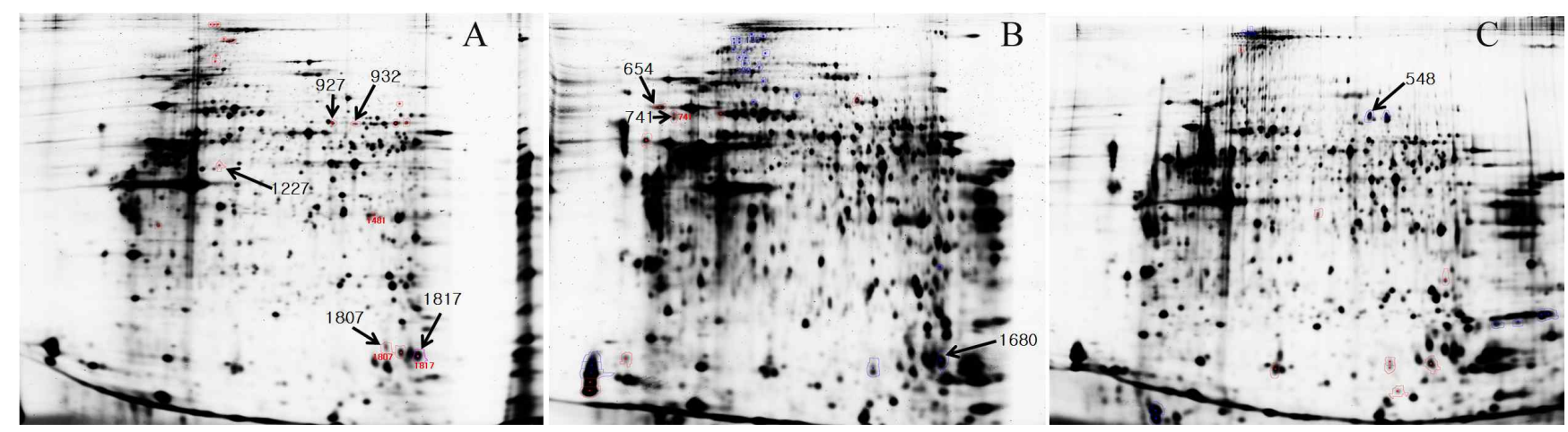

Fig. 4. 2D-DIGE of BSC proteins. Protein extracts of BSC from longissimus dorsi, deep pectoral and semitendinosus muscle depots grown in IGF-1 or TS supplemented medium(day 9) were labeled with CyDyes Cy3, Cy5 and Cy2, respectively, and were mixed and separated on a 2-DE gel using $24 \mathrm{~cm} \mathrm{pH}$ 3-10 NL strips in the first dimension and 12\% SDS-PAGE gels in the second dimension. Gels were scanned to obtain single images, and the figures represented here are the overlay of the two dyes (Cy3, Cy5) of longissimus dorsi (A), deep pectoral (B) and semitendinosus (C) BSC proteins. The same gel, after fluorescence imaging, was stained with Flamingo pink and scanned. Differentially expressed protein spots as indicated in Table 3 are represented in the corresponding gels with arrows. 
Table 3. Differentially expressed proteins from IGF-1/TS treated bovine satellite cells from longissimus dorsi, deep pectoral and semitendinosus muscle depots

\begin{tabular}{ccccccc}
\hline No. & Spot No. & Abundance & Protein Name & Protein Score & Protein score $\%$ & Fold change \\
\hline \hline 1 & 1817 & Decreased & Uncharacterized protein C2orf10 & 51 & 64.379 & 2.2 \\
2 & 1807 & Decreased & C-jun-amino-terminal kinase-interacting protein 4 & 58 & 92.892 & 0.8 \\
3 & 1227 & Decreased & High affinity interleukin-8 receptor A & 49.2 & 46.08 & 1.2 \\
4 & 932 & Decreased & Tryptophan 5-hydroxylase 1 & 59.5 & 94.968 & 3.4 \\
5 & 927 & Decreased & Dihydropyrimidinase-related protein 2 & 58.9 & 94.222 & 2.8 \\
6 & 1680 & Increased & Hemoglobin subunit epsilon & 47.5 & 20.254 & 5.1 \\
7 & 654 & Decreased & Vimentin & 146 & 100 & 0.9 \\
8 & 741 & Decreased & Tubulin beta chain & 50.9 & 64.549 & 1.6 \\
9 & 548 & Increased & Collagen alpha-5(IV) chain precursor & 51.3 & 66.756 & 2.8 \\
\hline
\end{tabular}

Differential protein expression from bovine longissimus dorsi (S No. 1 to 5); deep pectoral (S No. 6 to 8); semitendinosus (S No. 9) muscle depots.

Further, we consider that the proteins that have the low expression during 10\% FBS treatment (high growth rate) are involved in inhibition of proliferation or cell death of BSC, hence the decreased expression of these proteins may be one reason for BSC to have the higher growth rate in FBS. However, proteins that are showing their high expression in 10\% CD-FBS with IGF-1/TS treatment may have their role in cell death as lower growth rates are observed. In contrast, the proteins which are having their low expression in $10 \%$ CD-FBS or with IGF-1/TS treatment may have their role in proliferation and whose lower expressions are responsible for lower growth rates.

\section{DISCUSSION}

Skeletal muscle growth involves a rise in both the cell number (hyperplasia) and the cell size (hypertrophy). Satellite cells have been shown to play a crucial role for postnatal muscle growth (Kamanga-Sollo et al., 2008) and for myofiber repair and regeneration. A better understanding of the involvement of satellite cells in postnatal myogenesis (formation of muscle tissue) and in muscle hyperplasia represents a powerful key to improve the efficiency of muscle growth in meat-producing animals. Hormones are the major regulatory factors that are critical for satellite cell proliferation and differentiation (McCuscker and
Campion, 1986; Thompson et al, 1989). An extensive array of hormones and growth factors modulate satellite cell proliferation, including growth hormone, thyroid hormone, and insulin. Among them, steroid hormones play a crucial role in the proliferation of BSC (Kamanga-Sollo et al, 2008). In the present study, we found that the BSC grown in $10 \% \mathrm{CD}$-FBS have low growth rates in comparison to the BSC grown in $10 \%$ FBS. CD-FBS is stripped off from important hormones such as estrogen, cortisone and progesterone (as per manufacturer's protocol) and all these belong to the steroid hormone group. Also, it has been demonstrated that charcoal-stripping of serum eliminates not only a variety of steroids, but also agents such as fatty acids and to a lesser extent, growth factors (Lindquist and de Alarcon, 1987). The results presented in our study are in perfect agreement with a previous study, where in it was shown that BSC grown in CD-FBS were showing less growth rate along with deformed morphology and when these cells were transferred to the medium containing FBS, the cells were showing increased proliferation rates (Lee et al, 2007). The majority of the hormonal growth promoters contain estrogenic, androgenic or a combination of these steroids, and have been used to improve muscle production and meat quality (Hayden et al, 1993; Johnson et al. 1996).

Steroid hormones are known to play a potential role in muscle 
growth through multiple mechanisms, influencing both hypertrophy of muscle fibers and the proliferation of satellite cells. The administration of androgenic and estrogenic steroids reportedly stimulated muscle growth in animals (Apple et al, 1991; Herschler et al, 1995). The muscle protein deposition can be increased by the implantation of an estrogen and progesterone mixture in particular with cattle (Apple et al, 1991; Hunt et al, 1991). Hence, the absence of these hormones in CD-FBS will have a profound effect on the proliferation of BSC from all the depots. Growth of $\mathrm{BSC}$ in $10 \% \mathrm{FBS}$ was high in comparison to $10 \% \mathrm{CD}$-FBS, while comparing the growth rate among the depots, the high growth rate was seen in LD BSC than DP and ST muscle depots. Previous studies have revealed that, myogenic cells have been shown to synthesize steroid hormones in vitro and in vivo (Hill et al, 1985). Hence, the BSC from different depots may have different intracellular hormone concentrations which are responsible for differential growth rate among the BSC from different depots. However, the differential role and concentration of steroids in different depots and its effect on proliferation of BSC remains unclear.

Comparing the growth of BSC grown in medium containing $10 \%$ CD-FBS or in $10 \%$ CD-FBS with IGF-1/TS, in both conditions, the growth rate was more or less similar. However, on comparison with $\mathrm{BSC}$ in $10 \% \mathrm{FBS}$, presence of both hormones (IGF-1/TS) did not affect the proliferation rates. This shows that, both hormones could not substitute the role of the hormones that are present in $10 \%$ FBS. Previous reports have shown the proliferative role of IGF-1 and TS on BSC (Kamanga-Sollo et al, 2008; 2004). The contrasting roles of these hormones in proliferation found in our study may be because, earlier studies have been conducted in examining the effect of IGF-1 on proliferation was in the presence of serum factors or conditioned medium that has other hormones except IGF-1 (Kamanga-Sollo et al, 2008). Also, previous studies have shown that IGF-1 alone was not sufficient to stimulate proliferation of BSC. It was revealed that IGF-1 along with other growth factors could induce proliferation of BSC (Thompson et al, 1989). Similar studies with rat satellite cells also reported the similar results, where in the IGF-1 alone was not able to induce proliferation(Allen and Boxhorn, 1987). Regarding the effect of androgens (trenbolone and testosterone) on proliferation of satellite cells, previous reports were contradictory. Thompson et al. (1989) and Doumit et al. (1996) have shown trenbolone and testosterone has no effect on the proliferation of rat satellite cells respectively, where as Kamanga-Sollo et al. (2008) have shown those androgens have proliferative effect on bovine BSC. However, in this study testosterone in the absence of other growth factors (CD-FBS) was not able to induce proliferation of BSC from three depots.

\section{Proteins differentially expressed in bovine satellite cells grown in FBS/CD-FBS}

Comparison of DIGE-2D data between BSC grown in medium containing FBS and CD-FBS revealed thirteen different proteins having low expressions. We have demonstrated that BSC from three depots showed a higher growth rate in FBS in comparison to CD-FBS. So, proteins that have a low expression during FBS treatment (high growth rate) are involved in inhibition of proliferation or cell death of BSC, hence the decreased expression of these proteins may help BSC to have a higher growth rate in FBS.

Transgelin, vimentin and actin are cytoskeletal proteins that play a role in the organization of the cytoskeleton. Transgelin-2 has been implicated to be over expressed during cell death (Brenda et al, 2007) and also proposed to be involved in senescence (Goodman et al, 2003). Vimentin is known to be a substrate to many caspases, it is cleaved by caspases- $3,-7$ and -6 during apoptosis (Byun et al, 2001). The proteolysis of vimentin promotes cell death by dismantling intermediate filaments and by generating a proapoptotic aminoterminal cleavage product that interferes with intermediate filament assembly (Byun et al, 2001). Actin was also shown to have anti-proliferative role, it was proved that actin was phosphorylated during cell death induction by activated protein kinase C-delta (Wang et al, 2008). Also, in this study we found decreased expression of stress-70 protein, which further indicates that BSC that are proliferating are under low stress levels, it was proven that higher stress levels decrease the proliferative rate (Halevy et al, 2001). Inwardly rectifying potassium channels are a specific subset of potassium selective ion channels. To date, seven subfamilies have been iden tified in various mammalian cell types (Kubo et al, 2005). They are the targets of multiple toxins, and malfunction of the channels has been implicated in several diseases (Abraham et al, 1999). Furthermore many anti-proliferative agents are mediated by this channel and decrease levels of this protein have always shown to have higher proliferative rates (Bock et al, 2002). Plasminogen 
was shown to induce cell death in endothelial cells and this process was mediated through glucose-regulated protein 78 (GRP78) (Braden et al, 2009).

Run and FYVE domain-containing protein 1 and lactotransferrin have their lower expression in SM depot and both these proteins were found to have anti-proliferative roles. FYVE domain-containing protein was shown to be involved in membrane trafficking of molecules (Burd and Emr, 1998). Proteins with this domain were shown to be involved in SMAD signaling, which leads to cell death (Mirua et al, 2000; Sebestyen et al, 2005). Bovine lactotransferrin was reported to be inducing cell death in the intestinal lymphocyte in rats, when given as a dietary intake (Spagnuolo et al, 2007). All the data presented above indicates that the proteins that are lowly expressed during FBS/CD-FBS treatment are having their roles in anti-proliferative effects and hence the decreased expression of such proteins may be one reason for higher BSC growth rates. However, the exact mechanism by which these proteins are involved in antiproliferative roles in BSC during proliferation will be an attention-grabbing research in the future.

\section{Differential protein expression of BSC from IGF-1 and TS supplemented medium}

Comparison of DIGE-2D data between BSC grown in medium containing IGF-1 and TS revealed nine different proteins having their differential expressions. Out of nine proteins, hemoglobin subunit epsilon and collagen precursor are the two proteins having their higher expression. As the BSC either in the presence of IGF-1 or TS was found to have low growth rates, the proteins that are highly expressed in this condition may involve in antiproliferative roles, bringing down the growth rate. Hemoglobin subunit epsilon belongs to hemorphins family i.e. endogenous fragments of $\beta$-globin, known to play a role in cell death by inducing cytotoxicity (Blishchenko et al, 2007). Hemoglobin subunit beta is known as LVV-hemorphin-7 and it participates in the cell death by the induction of cytolysis (Kampa et al, 1997). Collagen like proteins, endostatin was reported to inhibit proliferation of endothelial cells and further it was shown that endostatin causes cell cycle arrest at G1 phase of the cell-cycle during its course of action as anti-proliferative agent (Folkman, 2006).

The proteins that have the low expression during the growth of
BSC in the presence of IGF-1 or TS may have a role in proliferation and so their low expression may be a reason for the lower growth rate. Concurrent increase in IL-8 and IL-8 receptor expression induces autocrine signaling that may be functionally significant in initiating and promoting the progression of cell proliferation (Murphy et al, 2005). Tubulin was shown to have its role in proliferation and its functions range from cellular structure/shape, intracellular organelle transport and cellular secretion of growth factors to chromosome segregation, which are important for cell cycle(Bailey et al, 2004). Tyrptophan 5-hydroxylase 1 is the enzyme that catalyzes the rate-limiting step in the serotonin synthesis (Callebert et al, 2006) and this serotonin was proven to be involved in cell proliferation (Azmitia, 2001).

In summary, our study demonstrates the effect of removal of steroid hormones on the growth rate of BSC from different depots. Also, we found that neither IGF-1 nor TS can promote the growth rate of BSC independently, and were not able to substitute the roles played by steroid hormones present in FBS. Our present proteomic approach on different depots under hormonal deprivation and addition has revealed proteins that are differently expressed. The results obtained in our study could be the key in understanding the roles played by these proteins in cell proliferation or cell death during hormone deprivation and addition.

\section{REFERENCES}

1. Abraham, M. R., Jahangir, A., Alekseev, A. E. and Terzic, A. 1999. Channelopathies of inwardly rectifying potassium channels. J. 13:1901-1910

2. Allen, R. E. and Boxhorn, L. K. 1987. Inhibition of skeletal muscle satellite cell differentiation by transforming growth factorß. J. Cell. Physiol. 133:567-573.

3. Allen, R. E. and Rankin, L. L. 1990. Regulation of satellite cells during skeletal muscle growth and development. Proc. Soc. Exp. Biol. Med. 94:81-86.

4. Allen, R. E., Sheeha, S. M., Taylor, R. G., Kendall, T. L. and Rice, G. M. 1995. Hepatocyte growth factor activates quiescent skeletal muscle satellite cells in vitro. J. Cell. Physiol. 165: 307312.

5. Apple, J. K., Dikeman, M. E., Simms, D. D. and Kuhl, G. 1991. Effects of synthetic hormone implants, singularly or in combinations, on performance, carcass traits, and longissimus muscle palatability of Holstein steers. J. Ani. Sci. 69:4437- 
4448.

6. Azmitia, E. C. 2001. Modern views on an ancient chemical: Serotonin effects on cell proliferation, maturation, and apoptosis. Brain Res. Bull. 56:413-424.

7. Bailey, S. R., Polan, J. L., Munoz, O. C., Agrawal, M. C., and Goswami, N. J. 2004. Proliferation and $\beta$-tubulin for human aortic endothelial cells within gas-plasma scaffolds. Cardiovasc. Radiat. Med. 5:119-124.

8. Bhasin, S., Woodhouse, L., Casaburi, R., Singh, A. B., Bhasin, D. and Berman, N. 2001. Testosterone dose-response relationships in healthy young men. Am. J. Physiol. Endocrinol. Metab. 281:E1172-1181.

9. Blishchenko, E. Y., Sazonova, O. V., Kalinina, O. A., Yatskin, O. N.,. Philippova, M. M., Surovoy, A. Y., Karelin, A. A., and Ivanov, V. T. 2002. Family of hemorphins: co-relations between aminoacidsequences and effects in cell cultures, Peptides 23:903-910.

10. Bock, J., Szabo, I., Jekle, A. and Gulbinsa, E. 2002. Actinomycin D-induced apoptosis involves the potassium channel Kv1.3. Biochem. Biophys. Res. Commun. 295:526-531.

11. Braden, C., McFarland, Jerry Stewart, Jr., Hamza, A., Nordal, R., Davidson, D. J., Henkin, J. and Gladson., C. L. 2009. Plasminogen Kringle 5 induces apoptosis of brain microvessel endothelial cells: sensitization by radiation and requirement for GRP78 and LRP1. Cancer Res. 69:5537-5545.

12. Brenda, Y. T., Salumbides, C., Wang, David Z. Qian, Simon Williams, Burd, C. G. and Emr, S. D. 1998. Phosphatidylinositol (3)-phosphate signaling mediated by specific binding to ring FYVE finger domains. Mol. Cell. 2:157-162.

13. Byun, Y., Chen, F., Chang, R., Trivedi, M., Green, K. J. and Cryns, V. L. 2001. Caspase cleavage of vimentin disrupts intermediate filaments and promotes apoptosis, Cell Death Differ. 8:43-450.

14. Callebert, J., Esteve, J. M., Herve, P., Peoch, K., Tournois, C., Drouet, L., Launay, J. M. and Maroteaux, L. 2006. Evidence for a control of plasma serotonin levels by 5-hydroxytryptamine (2B) receptors in mice. J. Pharmacol. Exp. Ther. 317:724-731.

15. Campion, D. R. 1984. The muscle satellite cell: a review. Int Rev. Cytol. 87:225-251.

16. Cooper, R. N., Tajbakhsh, S., Mouly, V., Cossu, G., Buckingham, M. and Butler-Browne, G. S. 1999. In vivo satellite cell activation via Myf5 and $\mathrm{MyoD}$ in regenerating mouse skeletal muscle. J. Cell. Sci. 112:2895-2901.

17. Dodson, M. V., McFarland, D. C., Grant, A. L., Doumit, M. E. and Velleman, S. G. 1996. Extrinsic regulation of domestic animal-derived satellite cells. Domest. Anim. Endocrinol. 13: $107-26$

18. Doumit, M. E. and Merkel, R. A. 1992. Conditions for the isolation and culture of porcine myogenic satellite cells. Tissue and cell. 24:253-262.

19. Doumit, M. E., Cook, D. R. and Merkel, R. A. 1996 Testosterone up-regulates androgen receptors and decreases differentiation of porcine myogenic satellite cells in vitro. Endocrinology 137:1385-1394.

20. Florini, J. R. and Magri, K. A. 1989. Effects of growth factors on myogenic differentiation. Am. J. Physiol. 256:701711.

21. Folkman, J. 2006. Antiangiogenesis in cancer therapy-endostatin and its mechanisms of action. Exp. Cell. Res. 312:594-607.

22. Goodman, A., Goode, B. L., Matsudaira, P. and Fink, G, R. 2003. The Saccharomyces cerevisiae calponin/transgelin homolog Scp1 functions with fimbrin to regulate stability and organization of the actin cytoskeleton. Mol. Biol. Cell. 14: 2617-29.

23. Greene, E. A. and Allen RE. 1991. Growth factor regulation of bovine satellite cell growth in vitro. J. Ani. Sci. 69:146152

24. Halevy, O., Krispin, A., Leshem, Y., MCMurthy, J. P. and Yahav, S. 2001. Early-age heat exposure affects skeletal muscle satellite cell proliferation and differentiation in chicks. Am. J. Physiol. Regulatory Integrative Comp. Physiol. 281: R302-R309.

25. Hansen-Smith, F. M., Picou, D. and Golden, M. N. H. 1979. Muscle satellite cells in malnourished and nutritionally rehabilitated children. Neurol. Sci. 41:207-221.

26. Hayden, J. M., Williams, J. E. and Collier, R. J. 1993. Plasma growth hormone, insulin-like growth factor, insulin, and thyroid hormone association with body protein and fat accretion in steers undergoing compensatory gain after dietary energy restriction. J. Anim. Sci. 71:3327-3338.

27. Hellmann, U., Wemstedt, C., Gonez, J. and Heldin, C. H. 1995. Improvement of an "In-gel" digestion procedure for the micropreparation of internal protein fragments for amino acid sequencing. Anal. Biochem. 224:451-455.

28. Herschler, R. C., Olmsted, A. W., Edwards, A. J., Hale, T., Montgomery, R. L., Preston, S. J. and Sheldon, J. J. 1995. Production responses to various doses and ratio of estradiol benzoate and trenbolone acetate implants in steers and heifers. J. Ani. Sci. 69:2452-2462.

29. Hill, D. J., Crace, S. P., Nissley, Morell, D., Holder, A. T. and Milner. R. D. G. 1985. Fetal rat myoblasts release both 
rat somatomedin-C (SM-C)-in-like growth factor I QGF-I) and multiplication-stimulating activity in vitro: partial characterization and biological activity of myoblastderived SM-C/IGF-I. Endocrinology 117:2061.

30. Hunt, D. W., Henricks, D. M., Skelley, G. C. and Grimes, L. M. 1991. Use of trenbolone acetate and estradiol in intact and castrate male cattle: Effect of growth, serum hormones, and carcass characteristics. J. Ani. Sci. 69:2452-2462.

31. Johnson, B. J., Anderson, P. T., Meiske, J. C. and Dayton, W. R. 1996. Effect of a combined trenbolone acetate and estradiol implant on steroid hormone levels, feedlot performance, carcass characteristics and carcass composition of feedlot steers. J. Anim. Sci. 74:363-71.

32. Johnson, B. J., Halstead, N., White, M. E., Hathaway, M. R. and Dayton, W. R. 1998. Activation state of muscle satellite cells isolated from steers implanted with a combined trenbolone acetate and estradiol implant. J. Anim. Sci. 76: 2779-86.

33. Kamanga-Sollo, E., Pampusch, M. S., Xi, G., White, M. E., Hathaway, M. R. and Dayton, W. R. 2004 IGF-I mRNA levels in bovine satellite cell cultures: effects of fusion and anabolic steroid treatment. J. Cell. Physiol. 201:181-189.

34. Kamanga-Sollo, E., White, M. E., Hathaway, M. R., Chung, K. Y., Johnson, B. J. and Dayton, W. R. 2008. Roles of IGF-1 and the estrogen, androgen and IGF-1 receptors in estradiol-17ß-and trenbolone acetate-stimulated proliferation of cultures bovine satellite cells. Domest. Anim. Endocrinol. 35: 88-97.

35. Kampa, M., Bakogeorgou, E., Hatzolgou, A., Damianaki, A., Martin, P. M. and Castanas, E. 1997. Opioid alkaloids and casomorphin peptides decrease the proliferation of prostatic cancer cell lines (LNCaP, PC3 and DU145) through a partial interaction with opioid receptors. Eur. J. Pharmacol. 335:25565.

36. Kubo, Y., Adelman, J. P., Clapham, D. E., Jan, L. Y., Karschin, A., Kurachi, Y., Lazdunski, M., Nichols, C. G., Seino, S. and Vandenberg, C. A. 2005. International Union of Pharmacology. LIV. Nomenclature and molecular relationships of inwardly rectifying potassium channels. Pharmacol. Rev. 57:509-526.

37. Landry, F., Lombardo, C. R. and Smith, J. W. 2000. A method for application of samples to Matrix-Assisted Laser Desorption Ionization Time-of-Flight targets that enhances peptide detection. Anal. Biochem. 279:1-8.

38. Lee, E. J., Choi, J., Hyun, J. H, Cho, K. H., Hwanf, I., Lee, H. J., Chang, J. and Chi, I. 2007. Steroid effects on cell proliferation, differentiation and steroid receptor gene expression in adult bovine satellite cells. Asian-Aust. J. Ani. Sci. 20: 501-510.

39. Lindquist, D. L. and de Alarcon, P. A. 1987. Charcoal-dextran treatment of fetal bovine serum removes an inhibitor of human CFU-megakaryocytes. Exp. Hematol. 15:234-238.

40. Mampuru, L. J., Chen, S., Kalenik, J. L., Bradley, M. E. and Lee, T. 1996. Analysis of events associated withsSerum deprivation-induced apoptosis in $\mathrm{C} 3 \mathrm{H} / \mathrm{Sol} 8$ muscle satellite cells. Exp. Cell. Res. 226:372-380.

41. McCuscker, R. H. and Campion, D. R. 1986. Effect of growth-hormone secreting tumors on skeletal muscle cellularity in the rat. J. Endocrinol. 111:279-285.

42. Mirua, S., Takeshita, T., Asao, H., Kimura, Y., Murata, K., Sasaki, Y., Hanai, J., Beppu, H., Tsukazaki, T., Wrana, J. L., Miyazono, K. and Sugamura, K. 2000. Hgs (Hrs), a FYVE Domain Protein, Is Involved in Smad Signaling through Cooperation with SARA. Mol. Cell. Biol. 20:9346-9355.

43. Moss, F. P. and Leblond, C. P. 1971. Satellite cells as the source of nuclei in muscles of growing rats. Anat. Rec. 170:421-435.

44. Murphy, C., McGurk, M., Pettigrew, J., Santinelli, A., Mazzucchelli, R., Johnston, G. P., Montironi, R. and Waugh, D. J. 2005. Nonapical and cytoplasmic expression of interleukin-8, CXCR1, and CXCR2 correlateswith cell proliferation and microvessel density in prostate cancer. Clin. Cancer Res. 11:4117.

45. Rabilloud, T. 1998. Use of thiourea to increase the solubility of membrane proteins in two-dimensional electrophoresis, Electrophoresis 19:758-760.

46. Sebestyen, A., Barnaa, G., Nagya, K., Janosi, J., Paku, S., Kohut, E., Berczi, L., Mihalik, R. and Kopper, L. 2005. Smad signal and $\mathrm{TGFb}$ induced apoptosis in human lymphoma cells. Cytokine. 30:228-235.

47. Sinha-Hikim, I., Artaza, J., Woodhouse, L., Gonzalez-Cadavid, N., Singh, A. B. and Lee, M. I. 2002. Testosterone-induced increase in muscle size in healthy young men is associated with muscle fiber hypertrophy. Am. J. Physiol. Endocrinol. Metab. 283:E154-164.

48. Sinha-Hikim, I., Roth, S. M., Lee, M. I. and Bhasin, S. 2003. Testosterone-induced muscle hypertrophy is associated with an increase in satellite cell number in healthy, young men. Am. J. Physiol. Endocrinol. Metab.285:E197-205.

49. Spagnuolo, P. A., Bird, R. P. and Hoffman-Goetz, L. 2007. Effect of short-term dietary intake of bovine lactoferrin on intestinal lymphocyte apoptosis in healthy mice. Nutrition 
23:812-817.

50. Thompson, S. H., Boxhorn, L. K., Kong, W. Y. and Allen, R. E. 1989. Trenbolone alters the responsiveness of skeletal muscle satellite cells to fibroblast growth factor and insulin-like growth factor I. Endocrinology. 124:2110-2121.

51. Thompson, S. H., Boxhorn, L. K., Kong, W. Y. and Allen, R E. 1989. Trenbolone alters the responsiveness of skeletal muscle satellite cells to fibroblast growth factor and insulinlike growth factor I. Endocrinology 124:2110-2117.

52. Tonge, R., Shaw, J., Middleton, B., Rowlinson, R., Rayner, S., Young, J., Pognan, F., Hawkins, E., Currie, I. and Davison, M. 2001. Validation and development of fluorescence two- dimensional differential gel electrophoresis proteomics technology. Proteomics. 1:377-396.

53. Wang, S., Z, Ying., Y, Yun., Li, X., Guo-qiang, C., Yong-zong, Y. and Li-shun, W. 2008. Phosphorylation of b-actin by protein kinase C-delta in camptothecinanalog-induced leukemic cell apoptosis. Acta Pharmacol Sin. 29:135-142.

54. Yongfeng Wei, Tolib B. Sanni, Peter X. F., Atadja, J. and Pili, R. 2007. Antitumor effect of the histone deacetylase inhibitor LAQ824 in combination with 13-cis-retinoic acid in human malignant melanoma. Mol. Cancer. Ther. 6:70-81.

(Received December 2, 2009; Revised December 17, 2009;

Accepted December 21, 2009) 